\title{
Three new species, four new records, and an updated species key for males of Trichomyia (Brachiotrichomyia) Bravo \& Araújo, 2013 (Diptera, Psychodidae)
}

\author{
Maíra Xavier Araújo ${ }^{1,3}$, Freddy Bravo ${ }^{1,4}$ \& Claudiney Biral dos Santos ${ }^{2}$ \\ ${ }^{1}$ Universidade Estadual de Feira de Santana (UEFS), Departamento de Ciências Biológicas (DCBIO), Laboratório de Sistemática de Insetos \\ (LASIS). Feira de Santana, BA, Brasil. \\ 2 Universidade Federal do Espírito Santo (UFES), Centro de Ciências da Saúde (CCS), Unidade de Medicina Tropical. Vitória, ES, Brasil. \\ E-mail: claudineybiral@gmail.com \\ ${ }^{3}$ ORCID: 0000-0003-2447-9901. E-mail: mah.biology@gmail.com \\ ${ }^{4}$ ORCID: 0000-0003-0959-0767. E-mail: fbravo@uefs.br
}

\begin{abstract}
Three new species of Trichomyia (Brachiotrichoyia) (Trichomyiinae, Psychodidae), Trichomyia spatulata sp. nov., Trichomyia ciliata sp. nov., and Trichomyia recurva sp. nov. are described and illustrated. Additionally, we present new records of Trichomyia (Brachiotrichoyia) armata Barretto, 1954, Trichomyia (Brachiotrichoyia) quatei Bravo, 2001, Trichomyia (Brachiotrichoyia) inermis Barreto, 1954, and Trichomyia (Brachiotrichoyia) plumata Bravo \& Araújo, 2013 in Brazil. An identification key for males of the subgenus was updated to include the three new species.
\end{abstract}

Key-Words. New species; Moth-flies; Brazil; Neotropical Region.

\section{INTRODUCTION}

Brachiotrichomyia Bravo \& Araújo, 2013 is a neotropical subgenus of Trichomyia Haliday in Curtis, 1839 included in the subfamily Trichomyiinae (Psychodidae) with seven described species: T. (B.) armata Barretto, 1954; T. (B.) brasiliensis Satchell, 1956; T. (B.) inermis Barretto, 1954; T. (B.) plumata Bravo \& Araújo, 2013; T. (B.) quatei Bravo, 2001 from Brazil; T. (B.) pseudodactylis Quate, 1996 from Costa Rica; and $T$. (B.) risaraldensis Bejarano, Pérez-Doria \& Sierra, 2009b from Colombia (Bravo \& Araújo, 2013). The species of this subgenus can be easily recognized by the presence of four segments in the palpi, where the first two segments are partially fused, by the fusion of gonocoxites with hypandrium and by the posterior projection of the gonocoxites as long arms that each have long bristles at a proximal margin (Bravo \& Araújo, 2013).

Here are described three new species of Trichomyia (Brachiotrichoyia) from Brazil and included in the identification key of for the species of Trichomyia (Brachiotrichoyia) proposed by Bravo \& Araújo (2013). Moreover, four new records are presented.

\section{MATERIALS AND METHODS}

The specimens examined in this study were cleared with $10 \%$ potassium hydroxide $(\mathrm{KOH})$, dehydrated in ethanol, and mounted with Canada balsam on slides. The type specimens were deposited in Coleção Entomológica Professor Johann Becker do Museu de Zoologia da Universidade Estadual de Feira de Santana, Bahia, Brazil (MZFS). Terminology follows Cumming \& Wood (2009) and the specific terminology of Psychodidae follows Wagner \& Ibáñez-Bernal (2009). The term "arm of gonocoxite" refers to the posterior expansion of each gonocoxite.

\section{RESULTS}

Taxonomy

\section{Trichomyia (Brachiotrichoyia) spatulata Araújo \& Bravo sp. nov. (Figs. 1A-E)}

Diagnosis: Sensilla in concave pits on segments of the palpi 1 and 2; fourth segment of palpus 1.2 times the length of third segment; $\mathrm{CuA}_{2}$ ending approximately at the same point as medial fork; 
ejaculatory apodeme 0.6 times the length of the gonocoxal arm; cercus teardrop-shaped in ventral view; posterior arms of gonocoxite convergent, with apical feathered bristles; gonostylus paddle-shaped.

Description: Male: Head wider than long. Supraocular and occipital bristles arranged in a single row. Antennal socket quadrangular (Fig. 1A). Palpus with four segments, with the first two proximal, not observed articular membrane between them; first and second segments of palpus with sensilla in concave pit; fourth segment of palpus 1.2 times the length of third segment; palpus formula 1.0:0.9:0.9:1.0 (Fig. 1B). Antenna with flagellum lost; scape subcylindrical and pedicel subspherical approximately the same length (Fig. 1A). Wing folded in anal area in the preparation: apex of Sc without bristles, base of $\mathrm{R}_{4+5}$ without bristles; $\mathrm{r}-\mathrm{m}$ absent; medial fork basal to radial fork; $\mathrm{CuA}_{2}$ ending approximately at the same point as medial fork (Fig. 1C). Male terminalia: hypandrium and gonocoxites fused dorsally; gonocoxite longer than wide, glabrous; posterior arms of gonocoxite digitiform in dorsal view, approximately the same length of gonostylus, folded at apex, convergent, with feathered bristles on apex; gonostylus present, paddle-shaped, glabrous; cercus teardrop-shaped in ventral view (Fig. 1D); epandrium wider than long, glabrous, subrectangular; ejaculatory apodeme 0.6 times the length of gonocoxal arm (Fig. 1E); hypoproct ending near cerci with dorsal micropilosity; finger-like (Fig. 1E).

Material examined: Holotype male, Brazil, Amazonas, Manacapuru, WSW of Manaus, 03 $17^{\prime} 48^{\prime \prime} S$; $60^{\circ} 37^{\prime} 38^{\prime \prime}$, 18.IV.1998, leg. R.Q., R.N., P.E. (MZFS \#56212).

Etymology: The term originates from the Latin word spatulata, meaning spatulated, and refers to the shape of gonostylus.

Distribution: Known only from the type locality.

Female: Unknown.

Remarks: The male terminalia of the new species T. spatulata is similar to T. plumata by the teardrop-shaped form of the cercus and by the curved gonocoxite arms that converge to midline. The two species are differen-

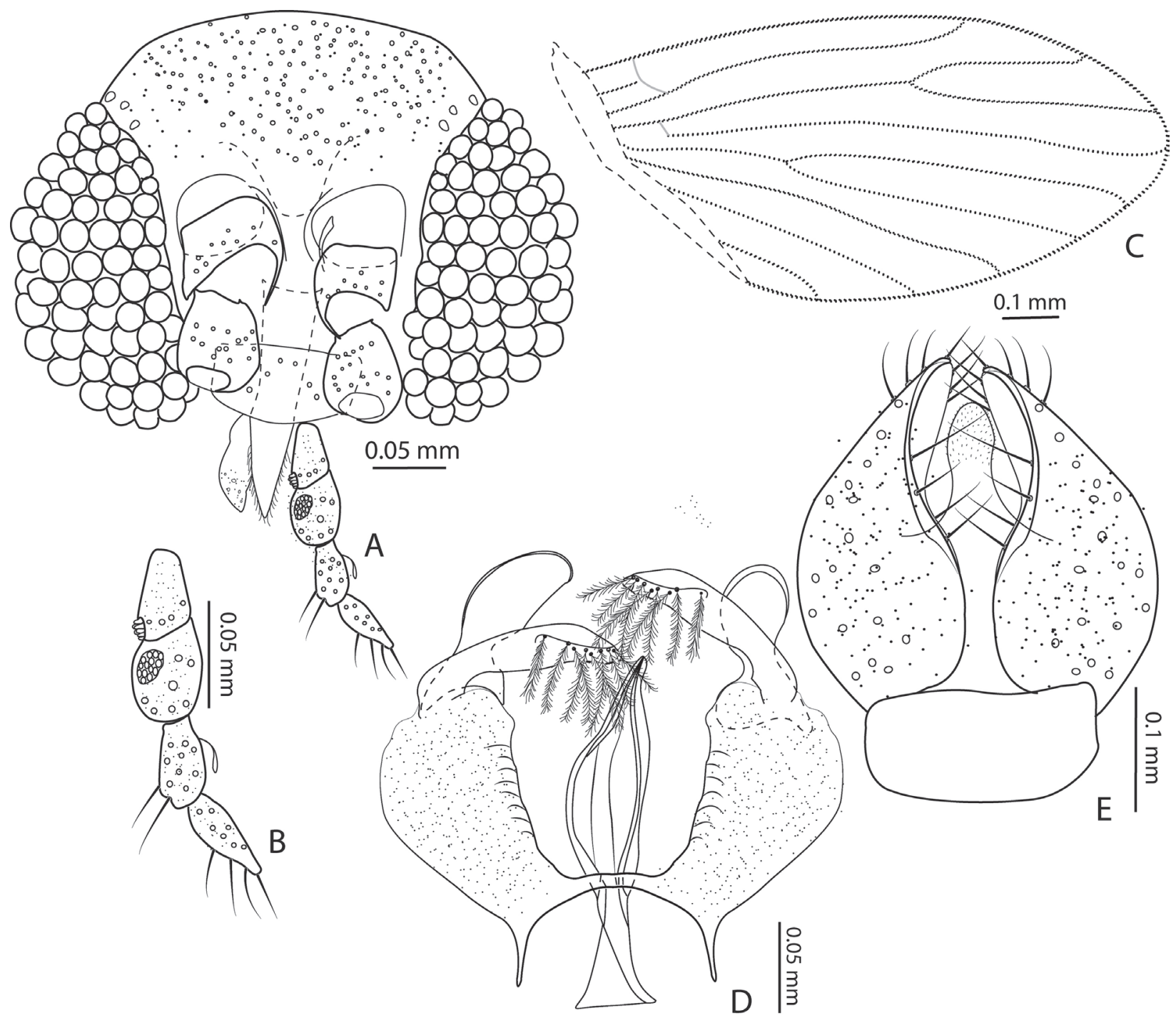

Figures 1. (A-E) Trichomyia spatulata sp. nov. (A) Head; (B) Palpus; (C) Right wing, folded in anal area; (D) Male terminalia, dorsal; (E) Cerci, epandrium, hypoproct. 
tiated by the format of the gonostylus, which is bladeshaped in T. plumata and paddle-shaped in the new species.

\section{Trichomyia (Brachiotrichoyia) ciliata Araújo \& Bravo sp. nov. (Figs. 2A-G)}

Diagnosis: Sensilla in concave pits on segments of the palpi 1 and 2; fourth segment of palpus 1.2 times the length of third segment; $\mathrm{CuA}_{2}$ ending approximately at the same point as medial fork; ejaculatory apodeme 1.4 times the length of the gonocoxal arm; cercus subrectangular in ventral view; posterior arms of gonocoxite convergent, with feathered bristles along $2 / 3$ apical; gonosty- lus blade-shaped, straight, pointy apex, approximately the same length of gonocoxal arm.

Description: Male: Head wider than long. Supraocular and occipital bristles arranged in a single row. Antennal socket subtriangular (Fig. 2A). Palpus with four segments, with the first two proximal, separated by a narrow articular membrane between them; first and second segments of palpus with sensilla in concave pit; fourth segment of palpus 1.2 times the length of third segment; palpus formula 1.0:1.0:1.5:1.3 (Fig. 2B). Antenna incomplete in all specimens; scape subcylindrical and pedicel subspherical approximately the same length; flagellomeres piriform, symmetrical, ascoids digitiform longer than flagellomere (Fig. 2C). Wing: Sc complete; sc-r present; base

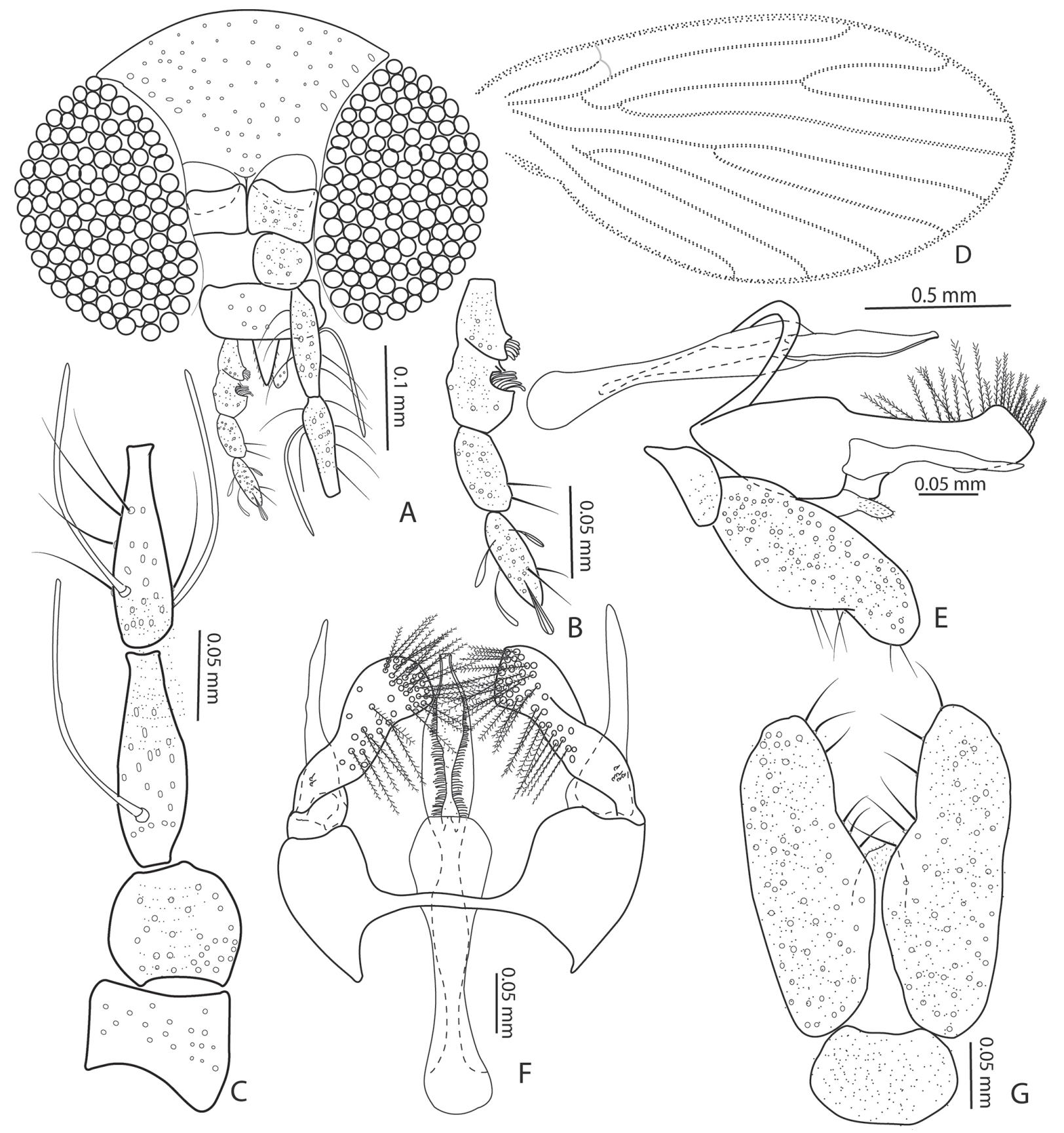

Figures 2. (A-G) Trichomyia ciliata sp. nov. (A) Head; (B) Palpus; (C) Scape, pedicel, first and second flagellomeres; (D) Right wing; (E) Male terminalia, lateral; (F) Male terminalia, dorsal; (G) Cerci, epandrium, hypoproct. 
of $\mathrm{R}_{4+5}$ without bristles; $\mathrm{r}-\mathrm{m}$ absent; medial fork basal to radial fork; $\mathrm{CuA}_{2}$ ending approximately at the same point as medial fork (Fig. 2D). Male terminalia: hypandrium and gonocoxites fused dorsally; posterior arms of gonocoxite digitiform in dorsal and lateral views (Figs. 2E-F), convergent, two times the length of gonostylus, apex rounded, with feathered bristles along $2 / 3$ apical; gonostylus bladeshaped, straight, pointy apex, approximately the same length of gonocoxal arm (Fig. 2F); epandrium wider than long, hirsute, subrectangular; cercus subrectangular in ventral view, basaly wider than apex; ejaculatory apodeme 1.4 times of gonocoxal arm (Fig. 2G); hypoproct short, with dorsal micropilosity; finger-like (Fig. 2G).

Material examined: Holotype male, Brazil, Espírito Santo, Cariacica, Reserva Biológica Duas Bocas, 28.viii.2008, dos Santos, C.B. leg. (MZFS \#56215); 5 paratypes male, Brazil, Espírito Santo, Cariacica, Roda d'agua, 29.viii.2008, leg. dos Santos, C.B. (MZFS \#56216, MZFS \#56217, MZFS \#56218, MZFS \#56219, MZFS \#56220); 3 paratypes male, Brazil, Espírito Santo, Cariacica, Reserva Biológica Duas Bocas, 05.x.2008, leg. dos Santos, C.B. (MZFS \#56221, MZFS \#56222, MZFS \#56223); 1 paratype male, Brazil, Espírito Santo, Aracruz, 09-11.i.2008, leg. dos Santos, C.B. (MZFS \#56224).

Etymology: Ciliata is derived from the Latin word cilium, meaning "eyelash" in reference to the fringe of hairs on the apex of the gonocoxite's arm.

Distribution: Known only from the type locality.

Female: Unknown.

Remarks: The new species and T. inermis are morphologically similar by the presence of feathered bristles in the arm of gonocoxite and by the elongated cercus with subparallel lateral margins. They differ by the length of the ejaculatory apodeme, which is long and narrow in T. inermis and short and wide in T. ciliata sp. nov.

\section{Trichomyia (Brachiotrichoyia) recurva Araújo \& Bravo sp. nov. (Figs. 3A-G)}

Diagnosis: Sensilla in concave pits on segments of the palpi 1 and 2; fourth segment of palpus with the same length of third segment; $\mathrm{CuA}_{2}$ ending approximately at the same point as medial fork; ejaculatory apodeme approximately the same length of gonocoxal arm; the cercus is elongated with a base wider than apex and the apex is bent; posterior arms of gonocoxite divergent, with feathered bristles throughout the arm, the apex directed outwards; gonostylus small, hemicircular.

Description: Male: Head wider than long. Supraocular and occipital bristles arranged bristles arranged in single row (Fig. 3A). Palpus with four segments, with the first two proximal, separated by a narrow articular membrane between them; first and second segments of palpus with sensilla in concave pit; fourth segment of palpus with the same length of third segment; palpus formula 1.0:0.5:0.9:1.0 (Fig. 3B). Antenna incomplete in the holotype and paratype; scape subcylindrical and pedicel subspherical approximately the same length; basal flagellomeres piriform, ascoids lost (Fig. 3C). Wing: Sc ending at apex; sc-r present; base of $\mathrm{R}_{4+5}$ without bristles; r-m absent; medial fork basal to radial fork; $\mathrm{CuA}_{2}$ ending approximately at the same point as medial fork (Fig. 3D). Male terminalia: hypandrium and gonocoxites fused dorsally; gonocoxite small; posterior arms of gonocoxite arched in dorsal view, divergent, longer than gonostylus, with feathered bristles throughout the arm, the apex directed outwards; gonostylus small, hemicircular, glabrous (Fig. 3G); cercus elongated, base wider than apex and apex bent (Fig. 3E); epandrium bilobated, glabrous; ejaculatory apodeme approximately the same length of gonocoxal arm (Fig. 3F); hypoproct with dorsal micropilosity, subtriangular, narrow posteriorly (Fig. 3F).

Material examined: Holotype male, Brazil, Bahia, Igrapiuna, Reserva Ecológica da Michelin, Pancada Grande, 18.v.2013, M. Aragão \& E. Menezes leg.; 1 paratype male (MZFS \#56214); 1 paratype male, Brazil, Espírito Santo, Cariacica, Roda d'agua, 29.viii.2008, leg. dos Santos, C.B. (MZFS \#562013).

Etymology: The term originates from the Latin word recurva, meaning bent back on itself or bent round, which refers to the shape the cercus apex.

Distribution: Known only from the type locality.

Female: Unknown.

Remarks: The new species differs from other species of Trichomyia (Brachiotrichoyia) mainly, by the form of the cercus, which is wider in the base than the bent apex and by the arched arms of gonocoxite.

\section{New records}

\section{Trichomyia armata Barretto, 1954}

Trichomyia armata Barretto, 1954: 127-129, figs. 1-12. Holotype male. Type-locality: Brazil (São Paulo) in MZFS. References: Barretto, 1954: 130 (key); Duckhouse, 1973: 6A.4 (catalogue); Bravo, 2000: 191 (citation); Bravo, 2001: 34, fig. 4 (palpus, male and citation), 35, figs. 9-10 (male terminalia and citation), 36 (citation); Bejarano et al., 2009a: 98, 100 (citation); Bejarano et al., 2009b: 299 (citation); Santos \& Leite, 2012: 42 (checklist); Bravo \& Araújo, 2013: 330, 331 (citation), 331-332 (new record - Paraná and diagnosis), 336 (key); Araújo \& Bravo, 2016: 7 (key), 12 (citation).

\section{Material examined}

3 males: Brazil, Espírito Santo, Cariacica, Roda d'agua, 29.viii.2008, leg. C.B. dos Santos (new record). 


\section{Distribution}

Brazil: São Paulo (Serra da Cantareira, Horto Florestal; Mogi das Cruzes, km 67 Rio de Janeiro - São Paulo, road); Paraná (Guarapuava; Jundiaí do Sul), Espírito Santo (Cariacica).

\section{Trichomyia quatei Bravo, 2001}

Trichomyia quatei Bravo, 2001: 32-34, figs. 1-3, 5-8. Holotype male. Type-locality: Brazil (Bahia) in MZFS. Distr.: Brazil (Bahia). References: Bejarano et al., 2009a: 98, 100 (citation); Bejarano et al., 2009b: 299 (citation); Santos \& Leite, 2012: 43 (checklist); Bravo \& Araújo, 2013: 330, 331 (citation), 334 (diagnosis), 336 (key); Araújo \& Bravo, 2016: 7 (key), 12 (citation).

\section{Material examined}

2 males: Brazil, Espírito Santo, Santa Teresa, Reserva Ecológica Agusto Rushi, 16.xii.2011, leg. C.B. dos Santos (new record).

\section{Distribution}

Brazil: Bahia (Itabuna, CEPEC), Espírito Santo (Santa Teresa).

\section{Trichomyia inermis Barretto, 1954}

Trichomyia inermis Barretto, 1954: 129-130, figs. 13-17. Holotype male. Type-locality: Brazil (São Paulo) in MZFS. Distr.: Brazil (São Paulo, Bahia and Amazonas).

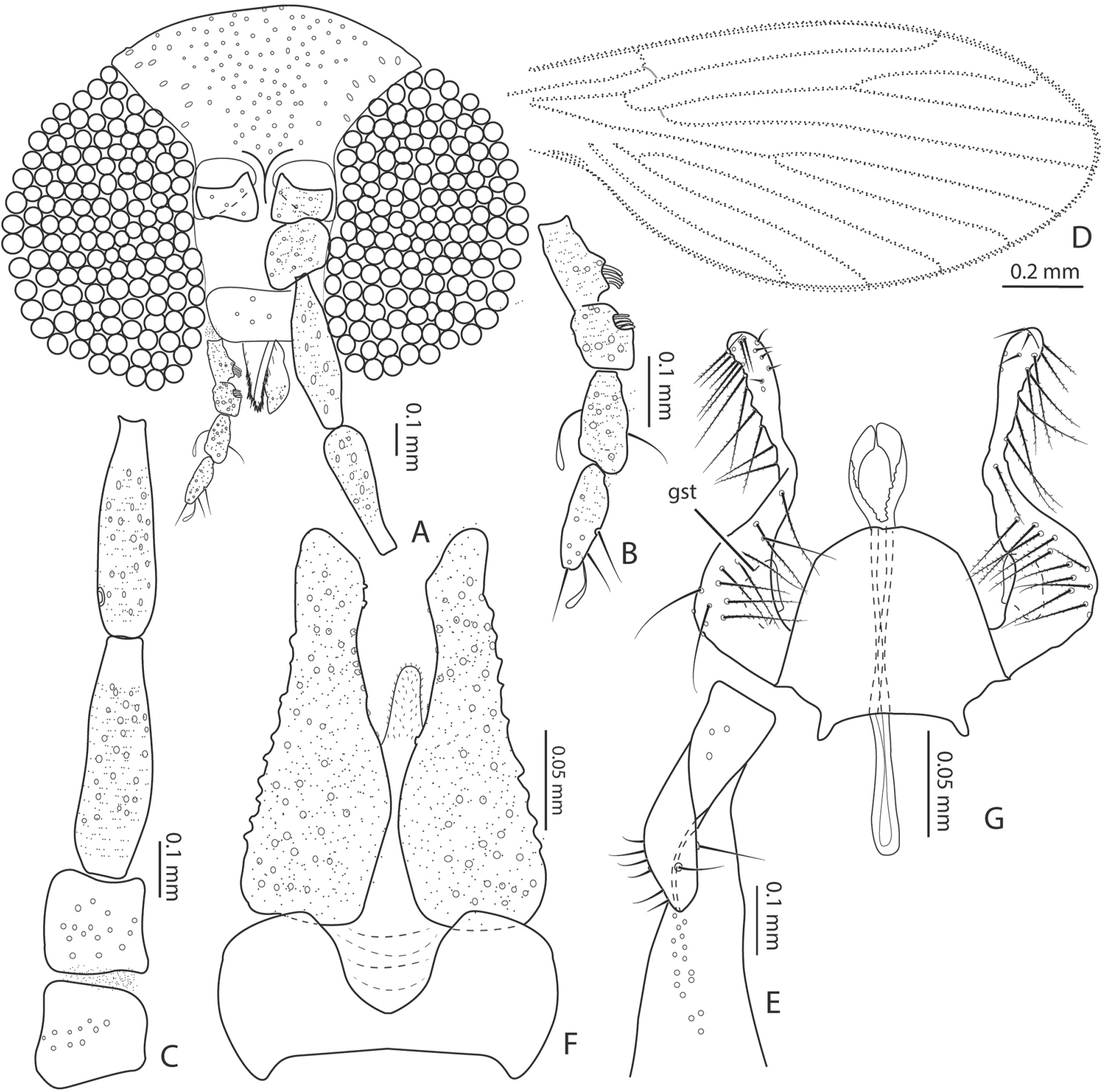

Figures 3. (A-G) Trichomyia recurva sp. nov. (A) Head (paratype); (B) Palpus; (C) Scape, pedicel, first flagellomeres; (D) Right wing; (E) Apex of cercus, dorsal view; (F) Cerci, epandrium, hypoproct; (G) Male terminalia, dorsal. (Abbreviation: gst = gonostylus). 
References: Barretto, 1954: 130 (key); Duckhouse, 1973: 6A.5 (catalogue); Bravo, 2000: 191 (citation); Santos \& Leite, 2012: 43 (checklist); Bravo \& Araújo, 2013: 330, 331 (citation), 332-333, figs. 1-7 (redescription and new record - Bahia, Amazonas), 336 (key); Araújo \& Bravo, 2016: 7 (key), 12 (citation), 73 (citation).

\section{Material examined}

1 male: Brazil, Bahia, Igrapiúna, Reserva Ecológica da Michelin, Pacangê, 15-16.xii.2012, leg. M. Aragão \& E. Menezes (new record); 1 male: Brazil, Espírito Santo, Santa Teresa, Reserva Ecológica Augusto Rushi, 16.xii.2011, leg. C.B. dos Santos (new record).

\section{Distribution}

Brazil: São Paulo (Serra da Cantareira, Horto Florestal; Mogi das Cruzes, km 67 Rio de Janeiro - São Paulo, road); Paraná (Guarapuava; Jundiaí do Sul), Bahia (Igrapiúna), Espírito Santo (Santa Teresa).

\section{Trichomyia plumata Bravo \& Araújo, 2013}

Trichomyia plumata Bravo \& Araújo, 2013: 334-335, figs. 8-12. Holotype male. Type-locality: Brazil (Amazonas) in MZFS. Distr.: Brazil (Amazonas). References: Bravo \& Araújo, 2013: 336 (key); Araújo \& Bravo, 2016: 7 (key), 12 (citation).

\section{Material examined}

1 male: Brazil, Mato Grosso, Barão de Melgaço, Bahia Sai Mariana, 03.iv.1998, leg. RF., FLS. \& RDN. (new record).

\section{Distribution}

Brazil: Amazonas (Manacapuru; Purupuru); Barão de Melgaço (Mato Grosso).

\section{Identification key}

Trichomyia spatulata, T. ciliata and T. recurva were included in couplet 6 of the identification key for the species of Trichomyia (Brachiotrichoyia) (Bravo \& Araújo, 2013). The key was modified from Bravo \& Araújo (2013: 336).

6(2). Cercus elongated, never teardrop-shaped in ventral view; arms of gonocoxite subparallel or divergent

- Cercus teardrop-shaped in ventral view; arms of gonocoxite convergent to midline...

7(6). Cercus with base wider than apex; apex of cercus bent in dorsal view; arms of gonocoxite divergent. T. (B.) recurva sp. nov. (Brazil: Espírito Santo) Cercus with lateral margins subparallel; apex of cercus not folded; arms of gonocoxite subparallel.
8(7). Arms of gonocoxite with truncate apex, ejaculatory apodeme narrow.

...T. (B.) inermis Barretto, 1954 (Brazil: São Paulo, Bahia, Amazonas)

- Arms of gonocoxite with rounded apex; ejaculatory apodeme wide T. (B.) ciliata sp. nov. (Brazil: Espírito Santo)

9(6). Gonostylus narrow, blade-shaped with truncate apex; ejaculatory apodeme long, approximately with the same length of arm of gonocoxite.

T. (B.) plumata Bravo \& Araújo, 2013 (Brazil: Amazonas)

- Gonostylus wide with rounded apex; ejaculatory apodeme short, shorter than arm of gonocoxite

T. (B.) spatulata sp. nov. (Brazil: Amazonas)

\section{ACKNOWLEDGMENT}

Maíra Xavier Araújo received a grant from Programa de Pesquisa em Biodiversidade (PPBio) - Fundação Amazônica de Defesa da Biosfera (FDB - 054/2017); Freddy Bravo has a research grant from CNPq № $(306441 / 2015-2)$.

\section{REFERENCES}

Araújo, M.X. \& Bravo, F. 2016. Description of forty four new species, taxonomic notes and identification key to Neotropical Trichomyia Haliday in Curtis (Diptera: Psychodidae, Trichomyiinae). Zootaxa, 4130: 1-76.

Barretto, M.P. 1954. Novas espécies de Trichomyia Hal. do Brasil (Diptera. Psychodidae). Folia Clinica et Biológica, 21: 127-137.

Bejarano, E.E.; Pérez-Doria, A. \& Sierra, D. 2009a. Trichomyia quimbaya, una nueva especie de Trichomyiinae (Diptera: Psychodidae) de la Cordillera Central de Colombia. Biota Neotropica, 9(4): 97-100.

Bejarano, E.E.; Pérez-Doria, A. \& Sierra, D. 2009b. Descripción de una nueva especie de Trichomyia (Diptera: Psychodidae) de los Andes Colombianos. Revista de la Sociedad Entomológica Argentina, 68(3-4): 295-300.

Bravo, F. 2000. Descrição de uma espécie de Trichomyia (Diptera, Psychodidae) do sudeste brasileiro, com comentários sobre a genealogia do gênero. Acta Biológica Leopoldensia, 22(2): 185-192.

Bravo, F. 2001. Trichomyia quatei (Diptera, Psychodidae), uma nova espécie do nordeste brasileiro. Acta Biológica Leopoldensia, 23(1): 31-37.

Bravo, F. \& Araújo, M.X. 2013. Trichomyia (Brachiotrichomyia subgen. nov.) plumata sp. nov. from the Neotropical Region (Diptera: Psychodidae: Trichomyiinae). Acta Entomologica Musei Nationalis Pragae, 53(1):329-338.

Cumming, J.M. \& Wood, D.M. 2009. Adult morphology and terminology. In: Brown, B.V.; Borkent, A.; Cumming, J.M.; Wood, D.M. \& Zumbado, M.A. (Eds.). Manual of Central American Diptera. Ottawa, NRC Research Press. v. 1, p. 9-50.

Duckhouse, D.A. 1973. Psychodidae. In: Papavero, N. (Ed.). Catalogue of the Diptera of the America South of the United States. São Paulo, Departamento de Zoologia da Secretaria de Agricultura. 6A, p. 1-29.

Santos, C.B. \& Leite, G.R. 2012. A new species of Trichomyia Haliday (Diptera: Psychodidae: Trichomyiinae) from the Brazilian Atlantic Forest, with a checklist of Western Hemisphere species. Zootaxa, 3573: 40-46.

Wagner, R. \& Ibáñez-Bernal, S. 2009. Psychodidae (sand flies, and moth flies or owl flies). In: Brown, B.V.; Borkent, A.; Cumming, J.M.; Wood, D.M. \& Zumbado, M.A. (Eds.). Manual of Central American Diptera. Ottawa, NRC Research Press. v.1, p. 319-336. 